\title{
Follow-up care and general pressure to treatment after discharge from psychiatric ward Lucie Kalisova ${ }^{1}$, Jiri Raboch*1, Thomas Kallert ${ }^{2}$ and EUNOMIA-study-group
}

\author{
Address: ${ }^{1}$ Psychiatric Department, 1st Medical Faculty, Charles University, Ke Karlovu 11, 12801 Prague, Czech Republic and ${ }^{2}$ Department of \\ Psychiatry and Psychotherapy, University Hospital Dresden, Fetscherstrasse 74, D-01307 Dresden, Germany \\ * Corresponding author
}

\author{
from WPA Thematic Conference. Coercive Treatment in Psychiatry: A Comprehensive Review \\ Dresden, Germany. 6-8 June 2007 \\ Published: 19 December 2007 \\ BMC Psychiatry 2007, 7(Suppl I):PI7 doi:I0.II86/I47I-244X-7-SI-PI7
}

This abstract is available from: http://www.biomedcentral.com/I47I-244X/7/SI/PI7

(c) 2007 Kalisova et al; licensee BioMed Central Ltd.

\section{Background}

The Czech Republic took part in the international EUNOMIA project, which pursued the application of coercive measures in psychiatric treatment. $5-35 \%$ of the patients with acute mental disorder are involuntarily admitted to psychiatric facilities in the Czech Republic. Previous reports showed that the majority of the patients in the Czech Republic feels to be admitted under duress of their family members, physicians and also the police. The subjective perception of the coercion is undoubtedly connected with an insufficient insight resulting from their illness. The aim of this presentation was to find out, in the group of involuntarily admitted patients, in which manner follow-up care proceeds after their release from the hospital, and to monitor, if any general pressure to adhere to the treatment exists.

\section{Methods}

Discharged involuntarily admitted patients were asked 3 months after admission whether they feel some pressure to adhere to treatment. We also monitored follow-up care using a special questionnaire form designed by the EUNOMIA group.

\section{Results}

The sample consisted of 202 involuntarily admitted patients. More than 90 per cent of them attended at least once a month a check-up at their out-patient psychiatrist. Only a small part of these patients utilized community services like day stationary services. The majority of the patients felt some danger that in case of non-observance of the treatment they would be restricted in some way (most often hospitalized again). Possible pressure is felt by them from the side of their family and of their outpatient psychiatrist.

\section{Conclusion}

We monitored the follow-up care in the group of involuntarily admitted patients in the Czech Republic. Patients are pushed to adhere to treatment by their relatives, but out-patient psychiatrists also play an important role. 